\title{
Pattern of private sector drug prescriptions in Galle: Adescriptive cross sectional study
}

\section{KP Ruwan C Prasad ${ }^{1}$, BDN Ranasinghe ${ }^{2}$}

${ }^{1}$ Lecturer, Department of Pharmacology, Faculty of Medicine, University of Ruhuna, Galle.

${ }^{2}$ Medical Officer, Karapitiya Teaching Hospital, Galle.

[Due to a technical error, this article was published without the tables in the previous issue of the Galle Medical Journal (2005; 10: 7-9)].

\begin{abstract}
Objectives: To describe the existing prescribing practice of the private sector doctors in Galle, Sri Lanka.
\end{abstract}

Setting: Three pharmacies in Galle municipality area.

Methodology: Data were collected during the period from 23 September 2002 to 19 October 2002 using a pre- tested questionnaire.

Results: 812 prescriptions with 2336 drugs were used in the analysis. According to the study criteria, 208(25.6\%) of total prescriptions were illegible. Rates of adherence to prescription writing guidelines were above $85 \%$. Average number of drugs per prescription written by consultants was $3.0 \pm 1.5$ (mean $\pm \mathrm{SD}$ ). $36.7 \%$ of drugs were prescribed by their generic name. Percentage of drugs prescribed from the essential drugs list of Sri Lanka was found to be $39.6 \%$.

Conclusion: The irrational practices of drug prescription identified among doctors in the private sector include poor use of generic names and illegible writing.

\section{Introduction}

Irrational use of drugs on a wide scale can have significant adverse effects on health care costs and on the quality of drug therapy and medical care [1]. There are many interrelated factors such as inadequate information, poor training and cultural beliefs underlying inappropriate use of drugs. Since the liberalisation of the pharmaceutical market in 1977, drug use in Sri Lanka, especially that of the private sector has been heavily influenced by similar factors. Even though this situation leaves adequate room for inappropriate drug use, studies reviewing local drug use patterns are uncommon. Therefore the magnitude of the problem remains little known. Good prescribing practice is an essential part of rational drug use. Prescription audits therefore are a useful way of assessing doctors' contribution to rational use of drugs in a country. Prescribing patterns in four institutions in Sri Lanka were assessed in 1988 [2]. They found several inappropriate prescription practices such as polypharmacy and extensive use of hypnotics and antibiotics. Our aim of carrying out this study was to describe the existing prescribing practice of the doctors in the private sector in Galle, Sri Lanka and to identify specific problems that need attention.

\section{Materials and Methods}

Data were collected from three selected pharmacies in Galle municipality area during 23 September 2002 to 19 October 2002. The number of customers attending the pharmacies per day was used as the criterion to select the pharmacies. Data were collected using a pre-tested questionnaire. All the data were collected exclusively from the information written on the prescriptions. Prescriptions with only name/s of drugs or those with names and the total quantity, prescriptions written by ayurvedic practitioners and veterinary surgeons, prescriptions for items other than medicine and those known to be written by foreign doctors were excluded from the study. If at least one of the components of a prescription cannot be read by the data collectors, that prescription was categorized as 'illegible'.

Designation of the prescriber was categorised into four groups. Those were consultants (doctors with postgraduate degrees in clinical disciplines), junior doctors (doctors with MBBS or BDS degree or equivalent qualifications), assistant medical 
practitioners (those appointed by Ministry of Health after completing a diploma course in medicine) and unknown (the designation not mentioned in the prescription). Core prescribing indicators defined by World Health Organisation and International Network of Rational Use of Drugs (WHO-INRUD) to audit drug use in health facilities were adapted for this study [3]. Whether a prescribed drug name was a generic or a brand one, was identified using Sri Lanka Drug Index MIMS Annual-Sri Lanka and Product Information Leaflets of respective medicine [4,5]. Drugs that the authors failed to identify as a generic/brand were categorised as “unidentified”. Using WHOINRUD guidelines on defining an antibiotic, every prescription was screened to see if it contained an antibiotic and the results were recorded [3]. Additionally anti-infective ear Preparations were also categorised as an 'antibiotic'. The statistical analysis was done using Epi Info-6 computer software. Chi-square test was used to assess the percentage differences.

\section{Results}

Prescriptions and drugs

Eight hundred and twelve prescriptions containing 2336 drugs were audited. The prescribers' profiles and the number of prescriptions written by them are shown in table 1. 324(13.8\%) illegible drugs and $69(2.9 \%)$ drugs, names of which could not be identified were excluded from further analysis. Five hundred and ninety three different types of brand and generic names were used by the prescribers in our study sample. The commonest drugs prescribed by consultants were prednisolone (42-3.3\%), Panadeine (26-2.0\%), M-cam (22$1.7 \%)$, diazepam (20-1.6\%) and Famo (18$1.4 \%)$.On the other hand amoxycillin (5-3.0\%), cloxacillin (5-3.0\%), Soframycin (4-2.4\%) and frusemide (3-1.8\%) were the drugs prescribed most frequently by junior doctors. However, in both strata the most commonly prescribed drugs accounted only for about $10 \%$ of total prescriptions.

\section{Accuracy of prescription writing}

208(25.6\%) prescriptions were found to be illegible according to the criteria used in the study.
Percentages of different elements of a prescription are shown stratified according to the designation of the prescriber in table 2 .

\section{Table 1 - Distribution of Prescriptions} According to the Designation of the Prescriber

\begin{tabular}{|l|l|}
\hline Prescriber & No. of Prescriptions \\
\hline Consultants & $516(63.5 \%)$ \\
MBBS Doctors & $78(9.6 \%)$ \\
AMPs * & $1(0.1 \%)$ \\
Dental Surgeons & $6(0.7 \%)$ \\
Unknown & $211(26.0 \%)$ \\
\hline Total & $\mathbf{8 1 2}(\mathbf{1 0 0 . 0 \% )}$ \\
\hline
\end{tabular}

* Assistant Medical practitioners

Table 2 - $n$ (\%) of Prescriptions not having different elements of a prescription given according to the designation of Prescribers

\begin{tabular}{|c|c|c|c|}
\hline & \multicolumn{2}{|c|}{ Consultants'Junior } & \\
\hline & Records & $\begin{array}{l}\text { Doctors' } \\
\text { Records }\end{array}$ & \\
\hline Date & $\begin{array}{c}40 \\
(7.8 \%)\end{array}$ & $\begin{array}{c}27 \\
(32.5 \%)\end{array}$ & $\mathrm{p}<0.01$ \\
\hline Name of patient & $\begin{array}{c}19 \\
(3.7 \%)\end{array}$ & $\begin{array}{c}4 \\
(4.8 \%)\end{array}$ & $\mathrm{p}=0.54$ \\
\hline Age of patient & $\begin{array}{c}154 \\
(29.8 \%)\end{array}$ & $\begin{array}{c}52 \\
(61.9 \%)\end{array}$ & $\mathrm{p}<0.01$ \\
\hline Gender of patient & $\begin{array}{c}180 \\
(35.1 \%)\end{array}$ & $\begin{array}{c}42 \\
(50.6 \%)\end{array}$ & $\mathrm{p}<0.01$ \\
\hline $\begin{array}{l}\text { Signature of the } \\
\text { prescriber }\end{array}$ & $\begin{array}{c}27 \\
(5.2 \%)\end{array}$ & $\begin{array}{c}4 \\
(4.8 \%)\end{array}$ & $\mathrm{p}=1.00$ \\
\hline Dose of drug & $\begin{array}{c}20 \\
(1.5 \%)\end{array}$ & $\begin{array}{c}3 \\
(1.9 \%)\end{array}$ & $\mathrm{p}=0.73$ \\
\hline $\begin{array}{l}\text { Frequency of drug } \\
\text { administration }\end{array}$ & $\begin{array}{c}50 \\
(3.8 \%)\end{array}$ & $\begin{array}{c}23 \\
(14.3 \%)\end{array}$ & $\mathrm{p}<0.01$ \\
\hline $\begin{array}{l}\text { Duration } \backslash \\
\text { total quantity }\end{array}$ & $\begin{array}{c}87 \\
(6.7 \%)\end{array}$ & $\begin{array}{c}10 \\
(6.5 \%)\end{array}$ & $\mathrm{p}=0.91$ \\
\hline
\end{tabular}




\section{Core prescribing indicators}

Comparison between consultants and junior doctors with regard to WHO- INRUD coreprescribing indicators assessed in this study are given in table 3 . Average number of drugs per prescription ranged from $1-10$. About $50 \%$ of prescriptions contained 2 or 3 drugs / prescription. Two prescriptions had 9 and 10 drugs. Percentage of drugs prescribed by generic name was $36.7 \%$ accounting for 714 drugs while 1218 (62.7\%) drugs were written in brand names. $11(0.6 \%)$ drugs were written using both brand and generic names. The percentage of drugs prescribed from the essential drug list of Sri Lanka was found to be 39.6\% accounting for 769 drugs out of 1943 records in this study [6]. Percentage of prescriptions with an antibiotic prescribed in this study was $23.9 \%$ represented by 142 prescriptions.

Table 3 - n (\%) of WHO - INRUD Core Prescribing Indicators given according to the designation of prescribers

\begin{tabular}{|l|c|c|l|}
\hline & Consultants' & $\begin{array}{c}\text { Junior } \\
\text { Doctors' } \\
\text { Records }\end{array}$ & \\
\hline $\begin{array}{c}\text { Generic names } \\
\text { + Both names }\end{array}$ & $\begin{array}{c}463 \\
(36.4 \%)\end{array}$ & $\begin{array}{c}44 \\
(28.0 \%)\end{array}$ & $\mathrm{P}<0.05$ \\
\hline $\begin{array}{c}\text { Included in } \\
\text { EDL }\end{array}$ & $\begin{array}{c}484 \\
(38.1 \%)\end{array}$ & $\begin{array}{c}64 \\
(40.8 \%)\end{array}$ & $\mathrm{P}=0.51$ \\
\hline $\begin{array}{c}\text { Antibiotic/s } \\
\text { prescribed }\end{array}$ & $\begin{array}{c}83 \\
(23.1 \%)\end{array}$ & $\begin{array}{c}28 \\
(39.4 \%)\end{array}$ & $\mathrm{P}<0.01$ \\
\hline
\end{tabular}

${ }^{*}$ Genetic name + Brand name

${ }^{* *}$ Essential Drug List of Sri Lanka 1999

\section{Discussion}

In the present study few inappropriate prescription practices were identified. Local and international guidelines on how to write a prescription correctly is widely available and are usually taught to doctors as a part of their undergraduate training in medical schools [7,8]. Following such guidelines will ensure that prescriptions are correctly interpreted and leave no doubt about the intention of the prescriber. In the present study percentages of mentioning the name of patient, name of prescriber, dose, frequency of drug administration and duration of treatment on the prescriptions were at a satisfactory level of $>85 \%$. A smilar high degree of physician's adherence to the basic principles of prescription writing was observed in Ethiopia [9]. In 40 (7.8\%) occasions consultants have not written the date on their prescriptions. On the other hand, date was missing from 27(32.5\%) prescriptions written by junior doctors. Performance of both consultants and junior doctors were poor with regard to writing age and gender of the patient on their prescriptions. Age and gender were absent in 154 (29.8\%) and 180 (35.1\%) prescription orders written by consultants respectively. The figures for junior doctors were $52(61.9 \%)$ and $42(50.6 \%)$ respectively. In developed countries it is a legal requirement to state the age for children under 12 years [10]. The authors have no way of discerning how many of the prescriptions were for children. However, as no age restriction was imposed in selection criteria, percentage of children should be parallel to that of the general population. This inappropriate practice makes it difficult for the pharmacist to verify the dose and could lead to toxic effects of drugs especially in children.

The necessity to write the prescriptions legibly has been emphasized repeatedly $[8,10]$. Illegible prescriptions can lead to harmful effects and sometimes can be fatal too [1]. About one fourth of the prescriptions in this study were found to be illegible. Consultants were found to be writing illegibly significantly more than the junior doctors (Consultants vs. junior doctors - 162 (31.4\%) vs. $10(12.0 \%)-\mathrm{p}<0.001)$. This needs urgent remedial measures as consultants act as role models among junior staff. Average number of drugs per prescription written by consultants was found to be $3.0 \pm 1.5$ (mean \pm SD). Some authors have recommended cut off points for this drug use indicator [12]. However it is unclear at this time what the gold standard for this indicator as well as for other core prescribing indicators should be [3]. But drug utilisation studies done in many developing countries including Yemen, Sudan, 
Malawi, Bangladesh, and Nepal have revealed the average number of drugs per prescription to be between 1.3 and 2.2 [13]. However a study reviewing prescribing practices of consultants at Karachchi, Pakistan reported the average number of drugs / prescription to be 4.5 [14]. Though current morbidity and mortality patterns should be reviewed before commenting on an appropriate value for this prescribing indicator, studies from other third world countries suggest that there is room for improvement. Junior doctors' behaviour in comparison to that of consultants' was significantly worse with regard to generic prescription rate. Only 44 (28\%) drugs prescribed by the junior doctors were written using either generic name or both generic and brand names when the figure for consultants was 463 (36.4\%).

The only WHO-INRUD core-prescribing indicator that showed a favourable outcome in this study was the percentage of prescriptions with an antibiotic prescribed. The figure of $23.9 \%$ is relatively low compared to figures of $25 \%$ - $63 \%$ revealed in field tests in twelve developing countries [13]. Junior doctors' records carried an antibiotic / antibiotics in significantly more instances than that of consultants'. In the current study 28 (39.4\%) prescriptions written by junior doctors compared to 83 (23.1\%) among the consultants' prescriptions had at least one antibiotic written on their prescriptions. However this value may be an over estimation of the actual value as most junior doctors do not keep a stock of antibiotics with them. This is favoured by the fact that the two most commonly prescribed drugs among junior doctors being amoxycillin and cloxacillin.

Use of a limited drug list in the government sector dates from 1959 in Sri Lanka. In spite of this fact the percentage of drugs prescribed from the essential drug list of Sri Lanka was less than half of the figures observed in other countries that developed essential drug lists decades afterwards. In the government sector of Bangladesh, Tanzania and Nepal the percentage of drugs written from essential drug list was $85 \%, 88 \%$ and $86 \%$ respectively [13]. This low value of $39.6 \%$ is detected probably due to the higher number of drugs available for prescription in the private sector. In the current study, doctors have used
593 different types of drugs. In an earlier study in Sri Lanka, it has been revealed that when government hospitals used 87-107 drugs a private nursing home had used 201 drugs [2].

Irrational habits of drug use identified among doctors in Galle, Sri Lanka include poor use of generic names, incompletely written prescriptions and illegible writing. A few interventions have shown to be effective in improving these inappropriate practices [15]. However before planning similar interventions audits of this nature should be carried out in the government sector too to get a better understanding of the problem. This should be followed by qualitative methods of investigation to find out why these practices prevail [1].

\section{Acknowledgement}

The authors are grateful to Dr. WAA Wijayasiri for his help with the analysis of data and Dr. $\mathrm{MBH}$ de Silva for her assistance in data collection.

\section{References}

1. Quick JD, Rankin JR, Laing OR, et al. Managing drug supply: the selection, procurement, distribution and use of pharmaceuticals. $2^{\text {nd }}$ ed. Connecticut: Kuumarian press, 1997: 422-48.

2. Angunawala I, Tompson GB. Drug precribing patterns: a study of four institutions in Sri Lanka. International Journal of Clinical Pharmacology Therapy and Toxicology 1988; 26(2): 69-74.

3. How to investigate drug use in health facilities: selected drug use indicators. Geneva: World Health Organization, 1993 WHO/DAP/93.1: 1-87.

4. Sri Lanka Drug Index 1997.Sri Lanka: Ministry of Health, 1998.

5. MIMS Annual Sri Lanka 1999/ $20002^{\text {nd }}$ ed. Medi Media International Group, 1999.

6. List of Essential Drugs. $2^{\text {nd }}$ revision. Sri Lanka: Ministry of Health, 1999.

7. The Pharmacological Basis of Therapeutics. $9^{\text {th }}$ ed. USA: The McGraw Hill Companies Inc., 1996: 1697706.

8. Sri Lanka Hospitals Formulary. $2^{\text {nd }}$ ed. Colombo: Ministry of Health, Sri Lanka, 1994: 3-4.

9. Desta Z, Abdulwhab M. Prescription writing in Gondar out patient teaching hospital, Ethiopia. East African Medical Journal 1996; 73(2): 115-9. 
10. British National Formulary 41. London: British Medical Association and the Royal Pharmaceutical Society of Great Britain, 2001: 1-3.

11. Charatan F. Family compensated for death after illegible prescription. British Medical Journal 1999; 319: 1456.

12. Kshirsagar MJ, Langade D, Patil S, Patki PS. Prescribing patterns among medical practitioners in Pune, India. Bulletin of World Health Organization 1998; 76(3): 271-5.
13. Hogerzeil HV, Bimo. Field tests for rational drug use in twelve developing countries. The Lancet 1993; 342: 1408-10.

14. Das N, Khan AN, Badini ZA, Baloch H, Parkash J. Prescribing practices of consultants at Karachi, Pakistan. Journal of Pakistan Medical Association 2001; 51(2): 74-7.

15. De Santis G, Harvey KJ, Howard D, Mashford ML, Moulds RF. Improving the quality of antibiotic prescription patterns in general practice.The role of educational Intervention. Medical Journal of Australia 1994; 160(8): 502-5. 